\title{
Structural and Functional Insights into the Microtubule Organizing Centers of Toxoplasma gondii and Plasmodium spp.
}

\author{
Ramiro Tomasina ${ }^{1,2,}$ Fabiana González ${ }^{1,2}$, and Maria E. Francia ${ }^{1,2, *}$ \\ 1 Laboratory of Apicomplexan Biology. Institut Pasteur de Montevideo. Montevideo, Uruguay. \\ 2 Departamento de Parasitología y Micología. Facultad de Medicina-Universidad de la República. \\ Montevideo, Uruguay \\ * Correspondence: mfrancia@pasteur.edu.uy;
}

\begin{abstract}
Microtubule organizing centers (MTOCs) perform critical cellular tasks by nucleating, stabilizing and anchoring microtubule's minus ends. These capacities impact tremendously a wide array of cellular functions ranging from ascribing cell shape to orchestrating cell division and generating motile structures, among others. The phylum Apicomplexa comprises over 6000 singlecelled obligate intracellular parasitic species. Many of the apicomplexan are well known pathogens such as Toxoplasma gondii and the Plasmodium species, causative agents of toxoplasmosis and malaria, respectively. Microtubule organization in these parasites is critical for organizing the cortical cytoskeleton, enabling host cell penetration and the positioning of large organelles, drive cell division and direct the formation of flagella in sexual life stages. Apicomplexans are a prime example of MTOC diversity displaying multiple functional and structural MTOCs combinations within a single species. This diversity can only be fully understood in light of each organism's specific MT nucleation requirements and their evolutionary history. Insight into apicomplexan MTOCs had traditionally been limited to classical ultrastructural work by transmission electron microscopy. However, in the past few years, a large body of molecular insight has emerged. In this work we describe the latest insights into nuclear MTOC biology in two major human and animal disease causing Apicomplexans; Toxoplasma gondii and Plasmodium spp.
\end{abstract}

Keywords: Microtubule organizing center; centrosome; Centriolar plaque; Plasmodium; Toxoplasma gondii; Ultrastructure expansion microscopy

\section{Introduction}

Invariably, microtubule organizing centers (MTOCs) perform critical cellular tasks by nucleating, stabilizing and anchoring microtubule's minus ends. These capacities are required for a wide array of functions, including ascribing cells with their characteristic shape and polarity, influencing resistance to mechanical forces, organizing the mitotic spindle, or acting as basal bodies (BBs) positioning and contributing to the nucleation and motility of cilia and flagella, and in this way, impacting intracellular transport, signaling and cellular differentiation. The fascinating biology of MTOCs, and their role in cellular life, health and disease has attracted scientists since the late 1800s (Scheer, 2014). A remarkable landmark in MTOC research history is Theodore Boveri's monograph 'Ueber die Natur der Centrosomen' written in the 1900's. His initial observations of mitotically dividing fertilized eggs of the nematode Parascaris equorum (then Ascaris megalocephala) established that the formation of mitotic spindles were controlled by a cellular organelle which persisted, replicated and was inherited. His coining of the term "centrosome" in 1887 (Boveri, 1887) sparked the interest for this structure which has provided, since, over 120 years of wonderland for microscopists and cell biologists. 
In the best studied higher eukaryote systems - such as humans and other animals- the centrosome performs the majority of the MTOC aforementioned functions. Animal centrosomes are characterized by the presence of two microtubule-based barrels known as centrioles. Centrioles are precisely organized. Centriolar microtubules organize following a nine-fold radial symmetry determined by a foundational structure known as the cartwheel. The cartwheel is a structure formed onto a preexisting centriole ( $a$ "mother" centriole), guided by the self-assembling properties of the Spindle assembly abnormal protein 6 homolog (SAS6) (Banterle et al., 2020; Culver et al., 2009; Dammermann et al., 2004; Gopalakrishnan et al., 2010; Kitagawa et al., 2011; Leidel et al., 2005; Pelletier et al., 2006). SAS6 interacts with other proteins, such as SCL-interrupting locus protein (STIL) and CEP135 to complete the cartwheel structure defining the geometric arrangement of the nine microtubule (MT) triplets. These triplets are each made up of a complete microtubule (A-tubule) and two incomplete tubules (named B and C). Precisely controlled microtubule polymerization completes the centriole cylindrical structure. The length of the centriolar microtubules growing apically from the cartwheel is tightly regulated and cell-type specific (Slep, 2016).

MT nucleation by the human centrosome occurs at all times. During interphase, the centrosome organizes the cell's cortical cytoskeleton. During cell division, MT organization is focused on the mitotic spindle. A complex matrix of proteins, known as the pericentriolar material (PCM), are orderly layered onto the centrioles. The PCM ascribes centrioles with their capacity for microtubule nucleation (Pereira \& Schiebel, 1997) (reviewed in Woodruff et al., 2014). The PCM's ability to nucleate microtubules is supported on multiple proteins out of which gamma-tubulin, the gammatubulin ring complex and their transient interactors along the cell cycle, play pivotal roles in catalyzing and regulating the MT nucleation process (Teixidó-Travesa et al., 2012).

It should be noted that in spite of the human centrosomes being by far the most intensely studied and the best understood both structurally and functionally, (largely owed to their preponderant role in underlying genetic conditions such as infertility, cancer and ciliopathies) their structure and organization is by no means the most representative found in nature. In fact, microtubule nucleation does not require centrosomes bearing bona fide centrioles; it can occur centriole-independent even in humans (Sanchez \& Feldman, 2017).

The phylum Apicomplexa comprises over 6000 single-celled parasitic protozoan species. Many of the apicomplexan are well known pathogens, causing immense morbidity and mortality both in humans and animals. Toxoplasma gondii, Plasmodium spp and Cryptosporidium spp, are causative agents of toxoplasmosis, malaria and cryptosporidiosis, respectively. Invariably all species within the phylum are obligate intracellular parasites, exhibiting multiple life stages - all happening within the host cells of definitive and intermediate hosts.

Microtubules organization in apicomplexan parasites encompases organizing the cortical cytoskeleton, required to enable host cell penetration and the positioning of large organelles (Kudryashev et al., 2010; Striepen et al., 2000), as well as, cell division and the formation of flagella in certain life stages.

Intracellular life is attained by active invasion. Active invasion implies the formation of a tight junction, which literally describes the intimate contact formed between the host cell plasma membrane and the parasite membrane.The tight junction constricts the parasite as it enters the cell, closing behind the parasite as invasion completes, thus avoiding the lysis of the infected cell. This invasion mechanism requires a robust cytoskeleton capable of penetrating the cell and withstanding mechanical forces experienced by the parasite as it enters. Proper cytoskeleton assembly is also required for motility. Apicomplexa have achieved such cortical microtubule stability by organizing a corset of subpellicular microtubules which twirl around the cell body, and extending through two thirds of 
the cell length. In conjunction with a specialized membranous system, this corset provides the required mechanical resistance as well as flexibility, allowing these parasites to invade our cells.

The subpellicular microtubules in Toxoplasma gondii and Plasmodium species are organized by ring-shaped MTOCs located at the cell apex, known as the apical polar ring (APR) (Harding \& Frischknecht, 2020; Hepler et al., 1966; Katris et al., 2014; N. S. Morrissette \& Sibley, 2002a, 2002b; Nichols \& Chiappino, 1987; Read et al., 1993; Russell \& Burns, 1984; Tran et al., 2010). In addition to the complexity of cortical MT organization during asexual development, the apicomplexan parasites also undergo sexual differentiation into macro and microgametes. While asexual stages are aflagellated, microgametes formed during sexual differentiation display flagella; mature Plasmodium sperm have a single flagella organized by a centriole-like structure composed of nine single A-type tubules (complete microtubules) and no central tube, embedded in an electron-dense mass. T. gondii microgametes, on the other hand, display two flagella, and the structure of their originating BB remains debatable (Francia et al., 2015; Tomasina \& Francia, 2020).

Whether BBs derive from a repurposed MTOC previously present in the asexual stages or distinct MTOCs are assembled de novo, is also unclear. However, recent data has shed light onto the process in Plasmodium. Plasmodium simultaneously forms eight flagellated sperm cells (Francia et al., 2015; Sinden et al., 1976; Sinden \& Smalley, 1979). Isotropic parasite expansion combined with whole proteome labeling (Pan-UExM) allowed visualization of the BB formation kinetics with unprecedented temporal resolution. BBs were shown to simultaneously form from a deuterostome-like structure (an MTOC originating proteinaceous matrix devoid of centrioles). In addition, a proteinaceous matrix was found linking the newly formed BBs with the nuclear MTOC, thereby physically linking both MTOCs in these cells (Rashpa \& Brochet, 2021). Partly owed to the life stage's experimental inaccessibility in the cat's gut, the route of BB biogenesis in the T. gondii male gametes is poorly understood. However, new technical breakthroughs allowing microgamete formation in vitro will likely expedite our understanding of the process in the coming years (Farhat et al., 2020; Martorelli Di Genova et al., 2019; Tomasina \& Francia, 2020).

Apicomplexa divide by divergent mechanisms (recently reviewed in Gubbels et al., 2021) (Fig. 1A and B). A diversity of sexual and asexual cell division modes are used by these parasites to proliferate. With a few notable exceptions within the phylum (e.g. Babesia - dividing by binary fission and Theileria spp - dividing by hitchhiking on the host cell's division apparatus) apicomplexa parasites can follow three division modes: endopolygeny, endodyogeny and schizogony. These modes vary in the extent to which chromosome replication is followed by nuclear mitosis and cytokinesis. In endopolygeny, chromosomes are replicated several times before the nucleus undergoes mitosis. Mitosis is then followed by parceling of multiple nuclei simultaneously into tens of daughter cells. In endodyogeny, each nuclear division cycle (encompassing DNA replication and nuclear mitosis) is followed by daughter cell formation and cytokinesis (Fig. 1A). Finally, in schizogony, nuclei undergo asynchronous DNA synthesis and mitosis, followed by a final round of synchronized mitoses coordinated with the simultaneous formation of several dozen daughter cells (Fig. 1B). Remarkably, Toxoplasma gondii divides by all three mechanisms as it transitions through its different life forms in different hosts (reviewed in Francia \& Striepen, 2014; Gubbels et al., 2021; Striepen et al., 2007; Tomasina \& Francia, 2020).

Each of these three modes of division encompass specific microtubule nucleation requirements. However, all modes pose similar challenging settings for microtubule nucleation from a standpoint of topological constraints. In all cases, chromosome segregation occurs by semi-closed mitosis, in the presence of a visibly unchanged nuclear envelope and indetectable chromatin condensation (Aikawa \& Beaudoin, 1968; Canning \& Sinden, 1973; Vivier \& Vickerman, 1974). In addition, nuclear division occurs at one point or another in synchrony with daughter cell cortical microtubule 
cytoskeleton formation. The latter occurs de novo - at the mother cell surface in schizogony or at the mother cell cytosol in endopolygeny and endodyogeny (Gubbels et al., 2021). The MTOCs for each forming daughter cell (i.e. an APR) must be precisely positioned and in concordance with the number of full chromosomal complements present at the mother cell at the time of daughter cell formation. Apicomplexans have solved this conundrum by separately controlling nuclear events and daughter cell formation evolving two functionally related and physically connected, albeit distinct, microtubule organizing centers (Francia et al., 2012).

Apicomplexans are a prime example of MTOC diversity and multiplicity of functional combinations within a single species. In this work we describe the latest insights into nuclear MTOC biology in two major human and animal disease causing Apicomplexans; Toxoplasma gondii and Plasmodium spp.

\section{NUCLEAR DIVISION ORGANIZATION BY MTOCs OF T. gondii and Plasmodium: STRUCTURAL AND FUNCTIONAL INSIGHT}

Centrosomal architecture in Apicomplexan parasites is highly diverse, and has been repeatedly referred to as being highly divergent. The latter holds true if regarded in reference to the centrosomal architecture of animals. Notable differences exist even amongst the centrosomes of Toxoplasma gondii and the Plasmodium species; the most outstanding one being that T. gondii bears MT-barrel based centrioles while Plasmodium species do not.

Schizogonic cell division in blood-stage Plasmodium encompasses asynchronous mitoses of multiple co-existing nuclei in a shared mother cell cytosol. Each individual nucleus controls its own MT nucleation requirements by bearing its own MTOC. The nuclear MTOC in Plasmodium was originally named the "centriolar plaque" (CP), and is also referred to in the literature as the "kinetic center." The CP was originally identified as an electron dense focus, proposed to be embedded in the nuclear envelope, and in close connection to a nuclear pore (Aikawa, 1966; Aikawa \& Beaudoin, 1968; Sinden et al., 1976). The CP was later shown to be home to many bona fide centrosomal proteins including centrin and $\gamma$-tubulin, and to house MT nucleation capacity (Arnot et al., 2011; Gerald et al., 2011).

During asexual development, blood-stage Plasmodium nuceli undergo dynamic changes of their nuclear MTs. Non-dividing nuclei bear a single CP, and intranuclear MTs. The latter form a "hemispindle" composed of a handful ( 5$)$ of bundled individual MTs. The hemi-spindle extends from the single CP to the opposite side of the nucleus. Upon the onset of S-phase, or DNA replication, the hemi-spindle retracts. This is followed by CP duplication and the formation of a mitotic spindle. At this point, the spindle presumably connects to the chromosome's kinetochores, but also keeps the CPs interconnected by extended MTs spanning the nucleus. Figure 4 in Aikawa \& Beaudoin, 1968 shows an illustrative transmitted electron micrograph of the spindle at this stage. More recently, this spindle has been visualized by fluorescence microscopy, and the term "interpolar" spindle coined (Liffner \& Absalon, 2021).

Early TEM work in Plasmodium berghei looking into sporogony - the mode of division used by the sporozoites life stage, present at the mosquitoes' salivary glands- defined the interpolar spindle as consisting of three distinct MT populations; the MTs spanning the duplicated CPs and the ones contacting the kinetochores, and MTs extending from one $\mathrm{CP}$ to a point beyond the equatorial plane 
of the spindle of unknown function (Schrével et al., 1977). As sister chromatids separate, and karyokinesis advances, the interpolar spindle retracts, and nuclear fission occurs.

The advent of immunofluorescence, in the early 90's, allowed further resolving the dynamic changes undergone by MTs in P. falciparum. Using anti-tubulin antibodies, it was shown that while the majority of spindles exist in $180^{\circ}$ configurations, the interpolar spindle can exist in a variety of other configurations which are nonetheless productive (Read et al., 1993). Spindle elongation was observable as chromatids separated from each other. It was also shown that the spindle evolves into a hemi-spindle upon sister chromatid separation, followed by an accumulation of nuclear diffuse tubulin staining. This suggests that the spindle-derived hemi-spindle disassembles following mitosis, and that no mitotic-derived spindle persists beyond mitosis (Read et al., 1993).

More recently, ultrastructure expansion microscopy (UExM) in P. falciparum has allowed a (literal) closer look into MT dynamics using fluorescent markers. In addition to providing an approximate four fold increase in resolution, the co-staining of MTs and a membrane stain (BODIPY), allowed for the first time the concomitant visualization of MT and nuclear envelope dynamics (Liffner \& Absalon, 2021). Concurrent observation of both MT and the NE is critical to understanding each structure's role in DNA segregation during closed mitosis.

The spindle pole body (SPB) of yeast is a multilayered structure either embedded in the nuclear envelope (in the budding yeast Saccharomyces cerevisiae) or inserted into the nuclear envelope prior to mitosis (fission yeast, e.g. Schizzosaccharomyces pombe). In either case, the SPB is not only responsible for nuclear MT nucleation during mitosis, but also organizes the cortical cytoskeleton. Like the CP in Plasmodium, SPBs are devoid of centrioles. Given its localization apposed to the nuclear envelope and the lack of bona fide centrioles, the $\mathrm{CP}$ has often been modeled after the yeast SPB. However, recent insights from UExM has revealed that the CP is in fact extranuclear, and is not embedded in the nuclear envelope at any point during mitosis. UExM, STED microscopy, and correlative light electron microscopy (CLEM) has further revealed that nucleation of microtubules resides within a chromatin free subcompartment within the nucleus, distal to the location of Centrin, a CP component, and proximal to a nuclear pore marker (Nup313) (Simon et al., 2021). This study has clearly established that whereas the $\mathrm{CP}$ is at the poles of the mitotic spindle, the $\mathrm{CP}$ is extranuclear, and MT nucleation capacity resides at a protein-dense region internal to the nucleus, but devoid of chromatin (Fig. 1D).

Importantly, centromeres - the chromosomes' regions onto which the kinetochore assembles- have been precisely mapped in P. falciparum. The histone variants PfCENH3, the prime molecular marker of centromeres, and PfH2A.Z, occupy a $4-4.5 \mathrm{~kb}$ region of similar size and sequence composition in all P. falciparum chromosomes. Immunofluorescence assay of PfCENH3 revealed that centromeres undergo dynamic changes in localization during division; they cluster to a single nuclear location prior to and during mitosis and cytokinesis but dissociate soon after invasion. Strikingly, however, the centromere clustering localization during mitosis does not coincide with the central region of the spindle. This region of the spindle has been regarded as a metaphase plate. Instead, centromeres seem to cluster at the base of the chromatin-free region from which MTs are nucleated during mitosis (See Figure 3c in (Simon et al., 2021)). This implies that either there is a short spindle at the site of centromere clustering - undetectable by various microscopy techniques, or that centromeres could be segregated by connecting to the nuclear envelope. Finally, it is possible that regions other than the centromeric chromatin bear physical connections to the nuclear envelope or the various spindles assembled throughout the life of the nucleus. Combining UExM, with centromere and MT markers, as well as BODIPY to visualize the nuclear envelope should clarify this matter. 
Much of our understanding of MTOC biology has come from analyzing their structural and functional variability in light of what has been described in humans or in other better studied model species such as yeast. Many studies have focused efforts in describing presence/absence of human centrosomal components in other eukaryotes. However, as mentioned above, these MTOCs represent only a minute fraction of the diversity present in nature.

Contrary to the plethora of information available for the yeast SPB (whose all 18 protein components have been mapped and localized (Seybold \& Schiebel, 2013)), or the human centrosome (whose proteome has been identified even with spatial resolution (Andersen et al., 2003; Danielsson et al., 2020)) information of the molecular make-up of the CP is scarce. To our knowledge, no systematic identification of CP components has been pursued. In fact, only a handful of molecular components have been definitely localized to the $\mathrm{CP}$ structure, and even fewer have been functionally validated (Table 1).

Plasmodium's genome seems to lack homologs of many of the well-known centrosomal proteins. Proteins like Spindle and centriole-associated protein 1 (SPICE), CEP192, CEP63, CEP152, Spindle assembly abnormal protein 5 (SAS-5),CP110, Centrobin,POC5, C2CD3,Ofd1, Polo-like kinase -1 (PIK-1) and PIK-4 are not present in the genome of this parasite. Cep135 (also known as Bld10), interacts with SAS6 to assemble the centriolar cartwheel in animals and Drosophila. Interestingly, despite not displaying centrioles, Plasmodium encodes for a homolog of Cep135 (In Plasmodium falciparum; encoded by PfML01_060030300) and SAS6 (Carvalho-Santos et al., 2010; Marques et al., 2015). It is plausible, however, that instead of forming the $C P$, these proteins could participate in basal body formation during gametogenesis.

Centrin and $\mathrm{\gamma}$-tubulin are the prime markers identifying the CP structure (Fowler et al., 2001). While the latter plays a role in MT nucleation, the former belongs to a family of EF-hand containing Calcium binding proteins, shown to play pivotal roles in centrosome duplication and segregation in other systems (Azimzadeh \& Bornens, 2007). The Plasmodium genome encodes for at least four Centrin-related proteins, whereby Centrin 1 and Centrin 3 are paralogues of mammalian centrins, and Centrin2 and Centrin 4 are alveolate-specific (Lee \& Huang, 1993). Both Centrin2 and Centrin3 have been shown to localize at the CP by immuno-EM and confocal microscopy (Lee \& Huang, 1993) in P. falciparum. In the rodent malaria species P. berghei, Centrin4 was shown by super resolution structured illumination microscopy (SIM) to dynamically change its localization, from cytoplasmic outside of mitosis, to the CP during nuclear division (Roques et al., 2019). In addition, PbCen4 was shown to associate with all other Centrins (PbCen1, 2 and 3); however, its role remains unclear, as its genetic abrogation had no effect on parasite cell division (Roques et al., 2019).

Akin to Plasmodium species, Toxoplasma gondii asexual stages bears two distinct MTOCs; the APR and the centrosome (N. Morrissette \& Gubbels, 2014) . The APR nucleates the subpellicular microtubules responsible for the parasite shape and motility. The centrosome nucleates the spindle microtubules crucial for mitosis (Hepler et al., 1966; N. S. Morrissette \& Sibley, 2002a, 2002b; Nichols \& Chiappino, 1987; Read et al., 1993; Russell \& Burns, 1984; Tran et al., 2010). The T. gondii centrosome is formed by two centrioles. Centrioles in this species are parallel to each other, and are much shorter than their animal counterparts; centrioles in T. gondii are at the limit of optical resolution measuring approximately $250 \mathrm{~nm}$ length and width (J.-F. Dubremetz, 1971; Francia \& Striepen, 2014; N. S. Morrissette \& Sibley, 2002b) (Fig. 2B). The T. gondii centrioles display the characteristic centriolar nine-fold radial symmetry, but are composed of single microtubules and a central tube. Single microtubule centrioles are rather rare in nature, but $\mathrm{T}$. gondii is not exclusive in this respect. Centrioles of one-cell embryos of Caenorhabditis elegans display a comparable morphology (O'Toole et al., 2003; Pelletier et al., 2006). However, single microtubule centrioles are associated with a lack of delta- and epsilon-tubulin coding genes in this species (Wang et al., 2017). Conspicuously, both 
tubulin family members are easily identifiable in the T. gondii genome (N. Morrissette, 2015) but are presumably not expressed in asexual stages as they are indetectable in transcriptomic and proteomic analyses (N. Morrissette, 2015).

Pioneer transmission electron microscopy experiments dating to the early sixties identified an electron dense structure in asexually dividing tachyzoites which was first called the E-body; "E" referred to the endodyogeny mode of division used by the parasite (van der Zypen \& Piekarski, 1967). Due to its high electron density, the E-body was initially thought to contain DNA. Because the E-body changed morphology during division, the authors proposed this to be the factor which could "instigate" endodyogeny (van der Zypen \& Piekarski, 1967). Dubremetz , Kalley and Hammond recoined the structure under the term "centrocone," as it is referred to nowadays (J.-F. Dubremetz, 1971).The E-body or centrocone is a conical elaboration outlined by an outwards folding of the nuclear envelope (Fig. 1C and 2A). It is always positioned adjacent to the centrosome. Microtubules of the mitotic spindle are housed within the centrocone during mitosis penetrating the nuclear envelope through pores, contacting the kinetochores. This structure was later shown to be conserved in other related apicomplexans, such as Eimeria (J.-F. Dubremetz, 1971; Kelley \& Hammond, 1972).

A protein carrying multiple membrane occupation and recognition nexus (MORN) motifs was shown to localize to ring structures at the apical and posterior end of the parasites, and to the centrocone (Gubbels et al., 2006). This marker has allowed dynamic visualization of the structure, defining that the structure persists, but varies, throughout the cell cycle. At the start of mitosis, when centrosomes have not detectably separated yet, the centrocone noticeably protrudes from the nuclear envelope. It then duplicates and segregates along with the centrosome to two distinct, albeit adjacent, sites of the nucleus.

Akin to what was previously described for Plasmodium, the centrosome is apposed to a nuclear pore (Fig. 1C). Centromeres of T. gondii cluster at the nuclear periphery permanently, at a location intimately related to that of the centrosome. MTs of the mitotic spindle are not present outside of mitosis. Centromere sequestration to the nuclear envelope in T. gondii is mediated by peripherally associated components of the nuclear pore complex (Francia et al., 2020).

In consonance for what has been described for Plasmodium, the T. gondii genome lacks homologs to many well-known centrosomal proteins. Protein coding genes for Spindle and centriole-associated protein 1 (SPICE), CEP135, CEP192, CEP63, CEP152, Spindle assembly abnormal protein 5 (SAS-5),CP110, Centrobin,POC5, C2CD3,Ofd1, Polo-like kinase -1 (PIK-1) and PIK-4 are absent from the genome (Table 1) (Hodges et al., 2010; Morlon-Guyot et al., 2017; N. Morrissette, 2015; Suvorova et al., 2015). Nonetheless, reciprocal BLAST searches in the genome, using the human centrosomal components as reference, have identified a number of relatively well conserved homologes. For example, homologes of SAS6, Centrins 1 thru 4, Centrin binding protein (Sfi1) and CEP250 have been not only identified in silico, but also validated as expressed proteins with centrosomal localization in T. gondii (Table 1).

As outlined above, SAS6 is a widely conserved centrosomal protein involved in ascribing centrioles with their characteristic morphology by means of assembling the centriolar cartwheel (Banterle et al., 2020; Culver et al., 2009; Dammermann et al., 2004; Gopalakrishnan et al., 2010; Kitagawa et al., 2011; Leidel et al., 2005; Pelletier et al., 2006). T. gondii bears two homologs of SAS6; TgSAS6 and TgSAS6-Like (de Leon et al., 2013). Interestingly though they are both located at MTOCs in T. gondii's asexual stages, TgSAS6 is a centrosomal protein while TgSAS6L locates close to the APR (de Leon et al., 2013). Conspicuously, observation of a canonical cartwheel at the proximal end of centrioles has not been reported in T. gondii. The functional role of TgSAS6 at the centrosome 
remains unexplored. TgSAS6L is not essential for parasite survival. However, its characterization led the authors to propose that the apical MTOC likely evolved from a flagellar nucleating BB (de Leon et al., 2013). This model is further supported by additional lines of evidence; for example, $\mathrm{T}$. gondii has repurposed the algal derived striated fiber assemblings (SFAs) to connect the centrosome to the apical MTOC. SFA proteins normally function anchoring BBs (Lechtreck et al., 2002), but in T. gondii they serve to position the daughter cell's APR during division (Francia et al., 2012).

Three centrin homologs have been identified and characterized in T. gondii; all of which localize to the centrosome (Hu et al., 2006). In addition, Centrin2 localizes to the APR and to the parasite's basal end. Centrin3 localizes also to the conoid (Hu et al., 2006). BLAST searches for additional Centrin homologues identify an additional homologue, bearing the most similarity to PfCen 4 in $\mathrm{T}$. gondii (TgME49_237490) (Morlon-Guyot et al., 2017). Though no expression of the putative TgCen4 is detectable in the asexual life forms of T. gondii, high levels of the transcript are detectable in sexual stages (Ramakrishnan et al., 2019). This expression pattern could reflect the involvement of the putative TgCen4 in BB biology. BBs may be either "recycled" or de novo assembled in male gametes of T. gondii (Tomasina \& Francia, 2020). It is plausible that either of these processes requires use of a different/specialized protein set than those found in asexual centrosomes. However, this hypothesis awaits experimental validation.

Centrin-binding proteins - Sfi- are yeast SPB proteins important for its replication (Kilmartin, 2003). In T. gondii, Suvorova and collaborators identified a centrin-binding protein homolog denominated TgSfi1 (Suvorova et al., 2015). TgSfi1 localizes at the centrosome next to TgCentrin1 (Suvorova et al., 2015). Interestingly this protein does not have a homolog in Plasmodium. However, a protein bearing a centrin binding motif has been identified. It has been proposed that the later might play an akin function to that of TgSfi1, despite its lack of sequence conservation (Suvorova et al., 2015).

Centrosomal associated protein 250, also known as Cep250 or c-Nap1 (for centrosomal Nek associated protein) plays a role in maintaining centriole junction within the centrosome until the onset of mitosis in animals. A complex interplay of phosphorylation and dephosphorylation of Cep250 either prevents or triggers centriole disjunction in a cell-cycle dependent fashion (Hardy et al., 2014). Characteristically, human Cep250 bears four coiled-coiled domains. In T. gondii, Suvorova and collaborators identified TgCep250 (TGME49_212880) as a protein bearing seven predicted coiled-coiled regions - two of which display high similarity to that of HsCep250. Additionally, TgCep250-Like-1 was identified (TgCep250L1; TGME49_290620). This protein bears a single coiled-coiled domain but bears little homology to either HsCep250 or TgCep250 beyond this domain (Suvorova et al., 2015).

Fine localization by super-resolution microscopy of multiple protein components of the centrosome led to the proposition of a bi-modal T. gondii centrosome organization (Suvorova et al., 2015). An outer core and an inner core were defined based on two distinct protein localizations with respect to the nucleus. The outer core faces the cytosol, while the inner core faces the nucleus. The outer core bears TgSas6,TgCentrin1 and TgSfi1. Hence, this core is thought to contain the atypical pair of centrioles described in T. gondii. However, this has not been formally shown. TgCep250 has been shown to localize to both the outer and inner cores, while TgCep250L1 localizes exclusively to the inner core. In addition, the centrosomal protein CEP530 has been recently shown to localize "in between" cores defining then a third location within the centrosome (Courjol \& Gissot, 2018).

Functional insight on the role of the outer core has come from analyzing the functions of both TgCep250 and TgSfi1. TgCep250 has been described as required for keeping the outer core and the inner core connected during centrosomal replication (Chen \& Gubbels, 2019). Mutants of this protein display a dysregulation of inner and outer core replication, whereby the outer core over duplicates with respect to the inner core. Parasites displaying this phenotype fail to properly segregate 
the nucleus, and lose the synchrony between nuclear mitosis and daughter cell formation (Chen \& Gubbels, 2019). Conversely, a temperature sensitive mutant bearing a non-synonymous point mutation in the TgSfi1 coding gene over-duplicates the inner core of the centrosome, whilst the outer core remains unduplicated. Consequently, this mutant exhibits profound cell division defects and fails to properly segregate its chromatin (Suvorova et al., 2015). In both mutants, daughter cell assembly is severely impaired, displaying a characteristic drop in the number of daughter cells formed, and reinforcing the notion that outer core proteins play a pivotal role in orchestrating daughter cell formation.

Much less is understood about the inner core. This core has only been shown to house TgCep250, and TgCep250L1. The function of Cep250L1 has not been deciphered, hence, the precise role of the inner core remains ill-understood.

The mechanisms of MT nucleation by the T. gondii centrosome are not well understood. Characteristic electron density, corresponding to the PCM surrounding the centrioles, is not observable by electron microscopy in T. gondii. Consistently, homologues to many of the defining PCM core proteins in animals, such CEP192, pericentrin and CDK5RAP2 are seemingly absent from the T. gondii genome (Morlon-Guyot et al., 2017) (Table 1). However, it should be noted that these searches are at best limited by our anthropocentric approach to the question; even many of the homologues that we do find are only distantly related to their animal counterparts.

Although the molecular players governing MT nucleation and spindle formation remain poorly defined, an intranuclear spindle has been clearly shown to be nucleated from the area surrounding the centrosome. Spindle microtubules are clearly observable within the centrocone (Fig. 1C) (Aikawa et al., 1967; Aikawa \& Beaudoin, 1968; J. F. Dubremetz, 1973; Francia et al., 2020). This intranuclear spindle follows a cell cycle pattern originating from the centrosome, and growing towards the nucleus.The first step in the mitotic spindle formation entails recruitment of tubulin to the centrocone (Chen et al., 2015; Gubbels et al., 2006). This recruitment takes place at the end of G1 prior to the centrosome duplication (Chen et al., 2015). As the cell cycle progresses, the spindle grows reaching the chromosomes (Brooks et al., 2011; Francia et al., 2020; Francia \& Striepen, 2014).

Recent work identified a homolog of the microtubule plus end-binding protein EB1, known for its function as a mitotic spindle microtubule stabilizing factor in many systems (Galjart, 2010). TgEB1 has further allowed visualization of the dynamics of the mitotic spindle. TgEB1 localizes to the nucleus outside of division and quickly re-localizes to the centrocone region upon entry into M phase, coinciding with the time of spindle formation (Chun Ti Chen et al. 2015). Mutants of this protein display lagging chromosomes, reinforcing the notion that a healthy spindle is required for proper chromosome segregation in these parasites.

On the other hand, though PCM components are missing, proteins known to play pivotal roles in centrosomal MT nucleation have been identified. Importantly, $\gamma$-tubulin has been localized to centrioles, and more recently, finely mapped to the outer core (N. Morrissette, 2015; Suvorova et al., 2015). In most organisms, MT nucleation is carried out by $\gamma$-tubulin complexes, or $\quad \gamma$-TuSC. In animals, multiple $\quad \gamma$-TuSCs assemble with other proteins into $\quad \gamma$-tubulin ring complexes ( $\gamma$-TuRCs) (Kollman et al., 2010). However, $\quad \gamma$-Tusc have been shown to suffice for MT nucleation in some species (Vérollet et al., 2006). The T. gondii genome encodes for GCP4, but not for GCP5 and GCP6 of the $\mathrm{\gamma}$-TuRC ring complex (Morlon-Guyot et al., 2017). It is possible that MT nucleation could be orchestrated by the assembly of $\gamma$-TusC ring instead of $\gamma$-TuRC ring (Morlon-Guyot et al., 2017). 


\section{NUCLEAR DIVISION ORGANIZATION BY MTOCs OF T. gondii and Plasmodium: INSIGHT INTO REGULATORY NETWORKS}

Understanding the mechanism involved in the replication of the MTOC are crucial to coming closer to the molecular clues behind the speedy and flexible cell division of apicomplexan parasites.

In animal cells, new centriole biogenesis occurs at the onset of S-phase. The process is catalyzed by the phosphorylation of STIL by a polo-like kinase known as PLK4 (Bettencourt-Dias et al., 2005). This phosphorylation is "permitted" at S-phase whenby an inhibitory phosphorylation by CDK1/CyclinB is relieved in STIL (Zitouni et al., 2016). Phosphorylated STIL can recruit SAS6 to the mother centriole wall to initiate new cartwheel formation. The interaction between SAS6 and CEP135 allows cartwheel stabilization and interaction with MTs which will form the centriole barrels (Lin et al., 2013).

Once the centrosome has replicated, pre-existing centrioles remain attached to each other through a physical linker formed by a multi-protein complex (involving CEP250/C-nap1 and rootletin). The dissolution of this link is critical to allow semi-conservative centrosome segregation to opposing poles, whereby each centrosome will be formed by a mother (old) and a (new) daughter centriole. Cep250 is the substrate of Nek2A, a kinase that belongs to the group of NIMA-related kinases family. In mammalian cells, Nek2A is substrate of an additional kinase called Mst-2, and of Protein Phosphatase 1 (PP1). In addition, Mst2's activity is positively regulated by PLK-1. Phosphorylated Mst2 phosphorylates Nek2A, which subsequently phosphorylates Cep250 inducing centrosome diyuntion. Nek2A is dephosphorylated by PP1, reversing the process.

In P. falciparum, four Neks have been identified. PfNek-2 and PfNek-4 were shown to be essential for sexual development in the mosquito vector and consistently, are only expressed in the gametocyte stage. PfNek-1 is expressed both in male gametocytes and during asexual stages (Dorin-Semblat et al., 2011; Reininger et al., 2005, 2009; Xue et al., 2011). Interestingly, observation of PfNek1's localization by immunofluorescence assays in asexually replicating P. falciparum revealed that it localizes to dots near the nucleus at the ring and schizont stages, but switches to a more diffuse cytoplasmic localization in trophozoites (Dorin-Semblat et al., 2011). PfNek-1 was shown to in vitro phosphorylate Pfmap-2, an atypical P. falciparum MAPK homologue (Xue et al., 2011).

Conversely, seven Neks have been identified in T. gondii (Peixoto et al., 2010). TgNek-2 thru 7 remain unexplored. However, TgNek-1 was shown to localize at the centrosome at G1/S; the time of centrosome duplication in T. gondii (Chen \& Gubbels, 2013). In accordance with its predicted role, a mutant of TgNek-1 exhibits a single centrosome in asexualy dividing parasites. This presumably corresponds to a centrosome whose disjunction is inhibited (Chen \& Gubbels, 2013). Interestingly, the CEP250 homologs (TgCEP250) is not a substrate of TgNek-1 (Chen \& Gubbels, 2019). Given TgNek-1's localization at the outer core, and TgCEP250L1 localization to the inner core, TgCEP250L1 is likely not a substrate of TgNek-1 either. Analysis mapping phosphoproteome changes in the background of a TgNek-1 mutant could be informative as to the underlying cellcycle regulated mechanisms of centriole junction and disjunction in T. gondii.

A single PP1 homolog has been identified in each T. gondii, P. berghei and P. falciparum (Bhattacharyya et al., 2002; Delorme et al., 2002; Guttery et al., 2014; Hollin et al., 2019; Khalife et al., 2021; Yang \& Arrizabalaga, 2017) . Given their critical role in controlling proliferation in other organisms PP1 homologs in apicomplexans have been put forward as promising drug targets to block parasite division. 
The PP1 holoenzyme is conformed by a catalytic subunit highly conserved denominated protein phosphatase 1 catalytic subunit (PP1c), which forms a complex with different regulatory subunits. The diversity of regulatory subunits that modulates PP1c phosphatase activity is such that a "binding code" for PP1c has been proposed, whereby the different combination of these subunits creates holoenzymes with unique properties (Heroes et al., 2013). In fact, most of the PP1c surfaces are interaction interfaces with different proteins. This, in turn, limits PP1c evolutionary rate, making it one of the most highly conserved enzymes amongst eukaryotic lineages (Moorhead et al., 2008). It should be noted that PP1 plays numerous roles other than limiting centrosome separation in many organisms, however, discussing those extends well beyond the scope of this review.

Interactions of PP1c with different players control its spatio-temporal activity. One such interaction, relevant to centrosome disjunction, is that of PP1c with its specific inhibitor. The "Inhibitor 2" (I-2) is a cell-cycle regulated PP1c inhibitor which is specifically expressed in S and M phases. In animal cells, this protein localization to the pericentriolar area, coincides with an increase in the kinase activity of the Nek2A-Mst2-PP1 complex (i.e. an inhibition of the phosphatase activity of PP1)(Eto et al., 2002). An I-2 homolog has been shown to exist in T. gondii and is named TgI2. TgI2 was shown to inhibit TgPP1's phosphatase activity in vitro. This inhibition is critically dependent on TgI2's SILK and RVxF motifs, a feature conserved in the higher eukaryotes I-2s (Deveuve et al., 2017). In addition, A leucine-rich repeat protein family, TgLRR1, binds TgPP1 within the nucleus. This interaction, assayed using recombinant proteins, was shown to inhibit TgPP1's phosphatase activity in Xenopus oocytes, overriding the G2/M cell cycle checkpoint in this system (Daher et al., 2007). Overall, TgPP1 is predicted to play a pivotal role in controlling cell cycle progression, likely through a prominent role in centrosome duplication. Though its phosphatase activity has been shown to be critically dependent on TgPP1's interactions with its specific inhibitor TgI2, and its binding partner TgLRR1 (which likely limits its activity at the centrosome by compartmentalizing it to the nucleus), nothing is known about its substrates nor about its in vivo interaction with TgNek1. Elucidating these critical aspects of TgPP1's life could shed light onto ill-understood, yet critical, aspects of centrosome biology in T. gondii.

In P. berghei, live-cell and ultrastructural imaging, showed recently that PbPP1 cyclically localizes to the proximity of the nucleus, at a position apposed to that of NDC80, a marker of Plasmodium's kinetochores (Zeeshan et al., 2021). This localization coincides with the start of DNA synthesis/Sphase. Immunofluorescence assays revealed similar localization dynamics of the PP1 homolog in P. falciparum whereby a diffuse cytoplasmic and more intense foci near the nucleus could be observed (Paul et al., 2020). Interestingly, both PfLRR1 and PfI-2 homologs have been identified, suggesting that the players involved in regulating PP1's activity at the centrosome in higher eukaryotes could be conserved in Plasmodium (Pierrot et al., 2018). However, though a number of studies have focused on shedding light onto PP1's functions in gametogenesis, egress and host-parasite interactions (Gnangnon et al., 2019), through conditional mutagenesis, RNA-seq and proteomics, whether PP1 plays any role in Plasmodium's CP biology remains to be determined.

The coordinated and timely onset of successive cell cycle stages is largely controlled by Cyclin-dependent kinases (CDKs) in mammalian cells. Many of the CDKs control cell cycle progression by means of what are known as "checkpoints." Bona fide cell cycle progression check points - as defined by the stalling of one process when another one has not progressed properly - are seemingly absent in T. gondii. This phenomenon has been repeatedly documented by phenotypic characterization of cell division mutants. An illustrative example is the mutant of the kinetochore protein TgNdc80. TgNdc80 conditional knock-down parasites lose the connection between the nucleus and the centrosome. In these mutants, the nucleus "falls off" the mother cell, whilst it continues on with 
daughter cell assembly (Farrell \& Gubbels, 2014). On the flip side, mutants who lose the connection between the centrosome and the MTOC guiding daughter cell assembly, are able to undergo mitosis normally (Francia et al., 2012). Instead of checkpoints, temporally coinciding mutual physical tethers are assembled onto the centrosome. Proper spatial and temporal co-organization of cell division events is ensured in this fashion (Chen \& Gubbels, 2019; Francia et al., 2012).

Nonetheless, a number of Cdk-related kinases (Crks; TPK2, TgCrk1, TgCrk2, TgCrk4, TgCrk5 and TgCrk6) and in some cases their partner cyclins, have been identified and characterized in T. gondii (Khan et al. 2002; Alvarez and Suvorova 2017; Naumov et al. 2017). TgCrk6 and TgCrk4 are required for progression through S-phase and mitosis. These CRKs have been proposed to partake in the regulation of spindle assembly and centrosome duplication, respectively. Their cyclin partners have not been identified, nor have their substrates been deciphered.

Seven CRKs have been identified in Plasmodium ( PK5, PK6, Mrk1, Crk-1, Crk-3, Crk-5 and Crk4)(Deshmukh et al., 2016; Ganter et al., 2017) , as well as four cyclins (Cyc1, Soc2, Cyc3 and Cyc4) (Matthews et al., 2018; Roques et al., 2015). CRK5 interacts with cyclin SOC2. Together, these proteins have been shown to play a role in licensing DNA replication. Consistently, a P. berghei mutant of CRK5 exhibits fewer nuclear poles, no chromatin condensation, fails to undergo cytokinesis or form flagella(Balestra et al., 2020). PfPK6 is also proposed to regulate S phase entry, however, its precise function and its interactors remain unknown (Bracchi-Ricard et al., 2000). To our knowledge, which CRK/Cyclin pairs are specifically involved in catalyzing spindle formation or CP duplication in Plasmodium have not been identified.

Mitogen-activated protein kinases (MAPKs) are a conserved family of protein kinases that regulate signal transduction, proliferation, and development in eukaryotes. The genome of $\mathrm{T}$. gondii encodes for three MAP-related kinases; MAPKL1, MAPK2 and ERK7. ERK7 has been shown to be involved in APR homeostasis and biogenesis (Dos Santos Pacheco Nicolas et al., 2021). Conditional null parasites for this protein exhibit a striking phenotype whereby conoid assembly is completely abrogated. On the other hand, both MAPKL1 and MAPK2 have been implicated in the regulation of centrosome duplication. A temperature sensitive mutant of MAPKL1 over-duplicates the centrosome at restrictive temperature, leading to the assembly of an aberrant number of daughter cells (Suvorova et al. 2015). TgMAPKL1's substrates, however, remain unidentified. On the other hand, parasites lacking MAPK2 fail to duplicate their centrosomes, do not complete DNA replication and do not initiate daughter cell budding. However, MAPK2 mutant parasites continue to grow and replicate their mitochondria, Golgi apparatus and plastid-like organelle, the apicoplast (X. Hu et al. 2020). The latter two are known to segregate with the centrosome.

Aurora-related kinases are a family of serine/threonine kinases well known for critically regulating cell cycle progression in many organisms. P. falciparum and T. gondii each bear three homologues of these kinases (Berry et al., 2016; Solyakov et al., 2011). In P. falciparum these kinases are denominated: Pfark-1,-2,-3 and in T. gondii: TgArk-1,-2,3 (Berry et al., 2016; Reininger et al., 2011). T.gondii's Ark1-3 have been experimentally addressed and all are functionally related to licensing events of the cell cycle (Berry et al., 2016, 2018). TgArk- 1 has been proposed to play a role in the duplication of the spindle pole and the inner core of the centrosome (Berry et al., 2018). TgArk-2 is the only of three that is not essential for tachyzoite replication (Berry et al., 2016). Although it localizes at the intranuclear mitotic spindle, mutants of TgArk-2 are able to proliferate normally (Berry et al., 2016). TgArk-3 localizes at the outer core of the centrosome and has been linked with regulation of the budding process, as mutants for this protein fail to assemble daughter cells and complete cytokinesis (Berry et al., 2018; Suvorova et al., 2015). 
Three ARK homologues have been identified in P. falciparum; Pfark-1, -2, -3. Of these, Pfark1 has been experimentally explored. Pfark-1 has been shown to be essential in blood stages for parasite's survival, and it has been shown to functionally interact with PfNek-1 (Morahan et al., 2020; Reininger et al., 2011). PfArk-1 localizes at the spindle poles during mitosis. In metazoans, Aurora A localizes at the spindle during nuclear division (Reininger et al., 2011). Given its cell cycle stage dependent localization to the spindle, PfArk-1 has been proposed as the functional homolog of Aurora A (Reininger et al., 2011). Much less is known about PfArk-2: where it localizes, whether it follows a cell cycle-dependent pattern of localization, and its functions/substrates, remain undetermined (Reininger et al., 2011). In vitro assays showed PfArk-2 preference for myelin basic protein (Carvalho et al., 2013). Finally, PfArk-3 displays a perinuclear localization and is expressed at the onset of S phase (Carvalho et al., 2013). All three PfArks are essential for blood stage parasite survival (Carvalho et al., 2013).

\section{CLOSING REMARKS}

Though MTOC structures in Apicomplexa have captivated the interests of electron microscopists since the 60's, several limitations have precluded the identification of their molecular makeup. Mechanistic studies have been limited both by the minute sizes of the structures, and the difficulty in their purification: a characteristic inherent to their multiple connections to rather stable and resistant cytoskeletal structures. This has precluded the extended use of proteomic-based approaches for identification of centrosomal/CP proteins in either species.

In addition, the fast cell cycles of apicomplexan parasites preclude the detailed study of the various short-lived cell cycle stages of asexual proliferation, and the transitions between asexual and sexual life forms. For example, in asexually replicating T. gondii and Plasmodium, centrosome/CP duplication occurs at the onset of S-phase; a stage reckoned to last about half an hour in a 6 hour cell division cycle. In asynchronous growing cultures of T. gondii, only a minute fraction of all parasites will be at this stage, making the study of the process a literal "needle in a haystack" kind of a challenge.

Cell cycle synchronization tools have tremendously increased our capacity to discern the events taking place in the mitosis of human cells. Synchronization tools based on differential osmotic stress of schizont stages are available for Plasmodium blood-stages. These tools, however, only enrich for ring stages and scalability of in vitro cultures remains a challenge. Cell cycle synchronization tools, which do not significantly modify the biology of the parasite and maintain synchrony for a significant period, have not been reported for use in $\mathrm{T}$. gondii.

The puzzle of the various regulatory networks linking the different synchronous events of cell division in apicomplexans, has only recently started to come together. But again, the various life forms and complex regulatory networks operating simultaneously in asynchronously growing parasites, transitioning between asexual and sexual cycles, makes the puzzle seem like an unapproachable challenge.

However, many of these limitations began to be relieved with the widespread access to efficient mutagenesis tools, super-resolution optical microscopy and the application of extremely high-resolution electron microscopy techniques (such as Cryo-electron tomography and Correlative Light EM). More recently, the advent of UExM has democratized the access to higher resolution optical microscopy and fluorescence imaging (Bertiaux et al., 2021; Guizetti \& Frischknecht, 2021). The latter will most likely become the technique of choice in less well funded settings where access to state of the art super resolution microscopy is limited. Together these techniques have expedited progress in our molecular understanding of MTOCs and their associated structures in the last few years, 
particularly impacting our understanding of Plasmodium's CP role in MT nucleation and T. gondii's centrosome organization. In addition, tools to in vitro trigger the development of sexual stages of $\mathrm{T}$. gondii, allowing unprecedented access to flagella-forming stages (i.e. basal body biology!), are now available (Farhat et al., 2020; Martorelli Di Genova et al., 2019).

We envision that the next few years will see multiple breakthrough studies solving the fascinating puzzle of MTOC biology in T. gondii and Plasmodium, bringing us closer to both understanding the intricacies of these parasites' basic biology, and devising new strategies to interfere with their most destructive power; their ability to proliferate within us.

\subsection{Figures, Tables and Schemes}

A.

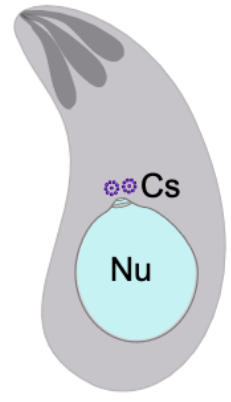

Non-dividing

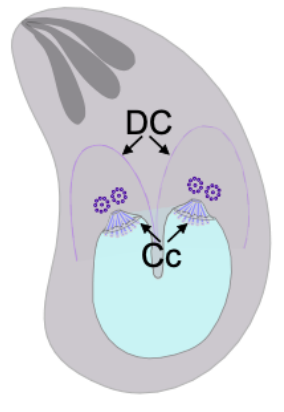

Endodyogeny
C.

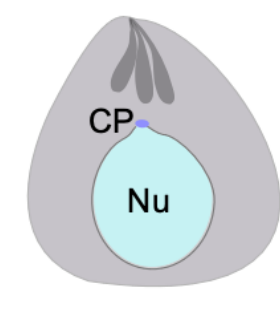

Non-dividing

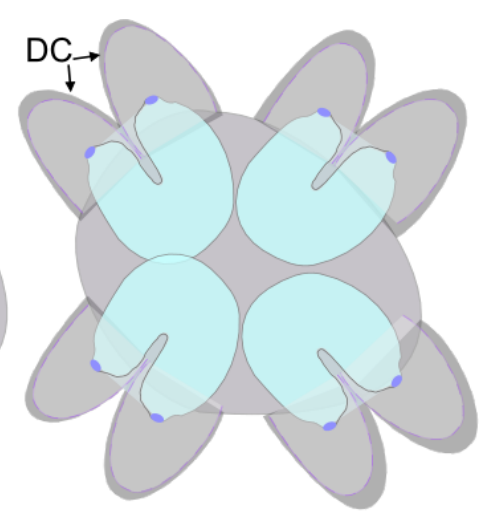

Schizogony
B.

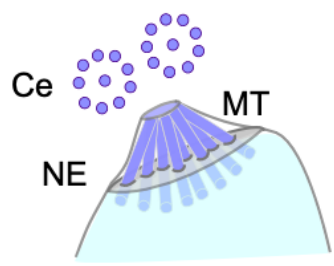

D.

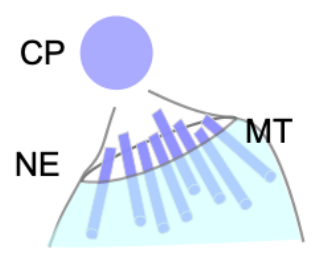

Figure 1. Cell division modes and nuclear MTOCs of asexually dividing Toxoplasma gondii and Plasmodium parasites. A. Schematic representation of a Toxoplasma gondii's tachyzoites nondividing and going through its cell division mechanism of endodyogeny, as indicated. Note that the intra-nuclear spindle is only assembled during division, while an elaboration of the nuclear envelope (marking the site of centrocone protrusion during cell division) is observable in nondividing parasites. Centrioles are shown in purple. $\mathrm{Nu}$; nucleus, Cs; centrosome, DC; daughter cells, Cc; centrocone B. Schematic representation of the centriole morphology, and the intra-nuclear spindle formed during Toxoplasma gondii division. Note that microtubules (MT) are nucleated within the centrocone a structure contained within the nuclear envelope (NE). MTs go through pores of the NE C. Schematic representation of asexual stage of Plasmodium spp both non-dividing and dividing by schizogony, as indicated. Note the centriolar plaque (CP), the nuclear MTOC lies in the proximity of the nucleus in all stages $\mathbf{D}$. Schematic representation of the centriolar plaque (CP). Microtubules (MTs) are nucleated during division in Plasmodium spp. at a region within the nuclear envelope (NE) devoid of chromatin, and physically distinct from the $\mathrm{CP}$ which lies outside the nucleus. 
Table 1. Toxoplasma gondii and Plasmodium falciparum homologs of mammalian centrosomal proteins

\begin{tabular}{|c|c|c|c|c|}
\hline $\begin{array}{l}\text { Gene ID in } \\
\text { Humans }\end{array}$ & $\begin{array}{c}\text { Toxo gene ID } \\
\text { (TGME49_) }\end{array}$ & $\begin{array}{l}\text { Plasmodium ID } \\
\text { (Pf3D7) }\end{array}$ & $\begin{array}{c}\text { Role in } \\
\text { Toxoplasma } \\
\text { gondii survival }\end{array}$ & $\begin{array}{c}\text { Role in } \\
\text { Plasmodiur } \\
\text { survival } \\
\end{array}$ \\
\hline SAS-4/C-PAP & 258710 & 1458500 & Essential by HTF & $\begin{array}{c}\text { Not essential } \\
\text { HTS }\end{array}$ \\
\hline CEP120 & 285210 & - & $\begin{array}{c}\text { Not essential by } \\
\text { HTS }\end{array}$ & - \\
\hline CEP76 & 226610 & - & $\begin{array}{c}\text { Not essential by } \\
\text { HTS }\end{array}$ & - \\
\hline POC1 & 216880 & 0826700 & Essential by HTS & $\begin{array}{c}\text { Essential b } \\
\text { HTS }\end{array}$ \\
\hline SAS6 & 306430 & 0607600 & $\begin{array}{c}\text { Not essential by } \\
\text { HTS }\end{array}$ & $\begin{array}{c}\text { Not essential } \\
\text { HTS }\end{array}$ \\
\hline SAS6L & 301420 & 1316400 & $\begin{array}{c}\text { Essential by } \\
\text { SGKO (de Leon } \\
\text { et al., 2013, p. 6) }\end{array}$ & $\begin{array}{c}\text { Not essential } \\
\text { HTS }\end{array}$ \\
\hline CEP135 & - & 0626500 & 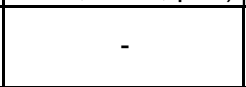 & $\begin{array}{c}\text { Not essential } \\
\text { HTS }\end{array}$ \\
\hline Centrin 1 & 247230 & 0107000 & Essential by HTS & $\begin{array}{r}\text { Not data } \\
\text { available }\end{array}$ \\
\hline Centrin 2 & 250340 & 1446600 & $\begin{array}{l}\text { Likely Essential } \\
\text { by SGKO } \\
\text { (Leung et al., } \\
2019, \text { p. } 2 \text { ) }\end{array}$ & $\begin{array}{c}\text { Not essential } \\
\text { HTS }\end{array}$ \\
\hline Centrin 3 & 260670 & 1027700 & Essential by HTS & $\begin{array}{c}\text { Not essential } \\
\text { HTS }\end{array}$ \\
\hline Centrin 4 & 237490 & 1105500 & $\begin{array}{c}\text { Not essential by } \\
\text { HTS }\end{array}$ & $\begin{array}{r}\text { Not essential } \\
\text { SGKO (Roqu } \\
\text { et al., } 2019\end{array}$ \\
\hline Sfi1 & 274000 & - & $\begin{array}{c}\text { Essential by } \\
\text { SGKO (Suvorova } \\
\text { et al., 2015) }\end{array}$ & - \\
\hline CEP164 & 314358 & - & Essential by HTS & - \\
\hline CEP170 & 201790 & 1307800 & Essential by HTS & $\begin{array}{c}\text { Not essential } \\
\text { HTS }\end{array}$ \\
\hline CEP110 & 211430 & 1032800 & $\begin{array}{c}\text { Not essential by } \\
\text { HTS }\end{array}$ & $\begin{array}{c}\text { Essential b } \\
\text { HTS }\end{array}$ \\
\hline kif24 & 287160 & 1245100 & $\begin{array}{c}\text { Not essential by } \\
\text { HTS }\end{array}$ & $\begin{array}{c}\text { Not essential } \\
\text { HTS }\end{array}$ \\
\hline EB1 & 227650 & 0307300 & Not essential by & Not essential \\
\hline
\end{tabular}

Adapted from (Morlon-Guyot et al., 2017)*HTS: high throughput CRISPR-Cas9 mutagenesis based **SGKO: single gene knockout 

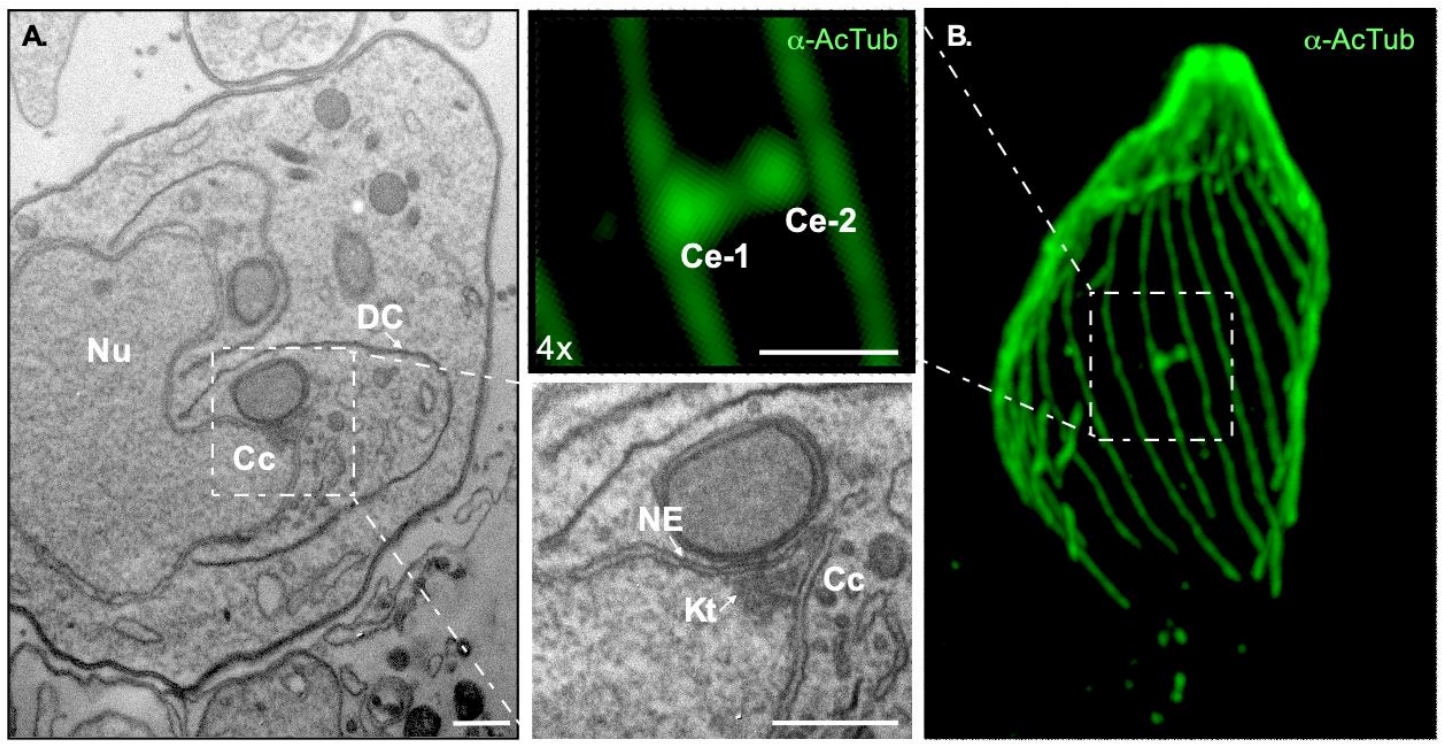

Figure 2. High Resolution images of MTOC associated structures in Toxoplasma gondii. A.Transmission electron micrograph of dividing Toxoplasma gondii's tachyzoites by endodyogeny. The centrocone $(\mathrm{Cc})$, the dividing nucleus $(\mathrm{Nu})$ in the process of segregation into two daughter cells (DC) are observable. The inset shows a detailed overview of the nuclear envelope (NE) forming the centrocone $(\mathrm{Cc})$ and the kinetochores $(\mathrm{Kt})$ B. Confocal microscopy image of ultrastructure-expanded non-dividing Toxoplasma gondii's tachyzoite labelled with anti-Acetylated Tubulin, as indicated. Note that using this technique the pair of centrioles (Ce1 and $\mathrm{Ce} 2$ ) forming the centrosome in this parasite are observable and can be resolved. Scale = $500 \mathrm{~nm}$ in all cases.

Author Contributions: “Conceptualization, R.T. and M.E.F.; writing-original draft preparation, R.T., F.G., M.E.F.; writing - review and editing, R.T., F.G., M.E.F. All authors have read and agreed to the published version of the manuscript."

Funding: Work at the Institut Pasteur de Montevideo is supported by an Institutional grant by Fondo para la Convergencia Estructural del Mercosur (FOCEM -COF 03/11).

Work in the Laboratory of Apicomplexan Biology is funded by grants to MF by Banco de Seguros del Estado, CSIC I+D 2019-15, and ACIP-RIIP 76-2017.

Acknowledgments: RT and FG are students of the PEDECIBA-Biologia graduate program. RT is funded by an ANII doctoral fellowship. MF is a PEDECIBA-Biología and Sistema Nacional de Investigadores researcher. The authors would like to thank the Transmission Electron Microscopy facility at the School of Sciences, Universidad de la República, and to the Advanced Bioimaging Unit at Institut Pasteur Montevideo, for their assistance in image acquisition.

Conflicts of Interest: The authors declare no conflict of interest. The funders had no role in the design of the study; in the collection, analyses, or interpretation of data; in the writing of the manuscript, or in the decision to publish the results. 


\section{References}

1. Aikawa, M. (1966). The Fine Structure of the Erythrocytic Stages of Three Avian Malarial Parasites, Plasmodium Fallax, P. Lophurae, and P. Cathemerium. The American Journal of Tropical Medicine and Hygiene, 15(4), 449-471. https://doi.org/10.4269/ajtmh.1966.15.449

2. Aikawa, M., \& Beaudoin, R. L. (1968). Studies on nuclear division of a malarial parasite under pyrimethamine treatment. The Journal of Cell Biology, 39(3), 749-754. https://doi.org/10.1083/jcb.39.3.749

3. Aikawa, M., Huff, C. G., \& Sprinz, H. (1967). Fine structure of the asexual stages of Plasmodium elongatum. The Journal of Cell Biology, 34(1), 229-249. https://doi.org/10.1083/jcb.34.1.229

4. Andersen, J. S., Wilkinson, C. J., Mayor, T., Mortensen, P., Nigg, E. A., \& Mann, M. (2003). Proteomic characterization of the human centrosome by protein correlation profiling. Nature, 426(6966), 570-574. https://doi.org/10.1038/nature02166

5. Arnot, D. E., Ronander, E., \& Bengtsson, D. C. (2011). The progression of the intra-erythrocytic cell cycle of Plasmodium falciparum and the role of the centriolar plaques in asynchronous mitotic division during schizogony. International Journal for Parasitology, 41(1), 71-80. https://doi.org/10.1016/j.ijpara.2010.07.012

6. Azimzadeh, J., \& Bornens, M. (2007). Structure and duplication of the centrosome. Journal of Cell Science, 120(13), $2139-2142$. https://doi.org/10.1242/jcs.005231

7. Balestra, A. C., Zeeshan, M., Rea, E., Pasquarello, C., Brusini, L., Mourier, T., Subudhi, A. K., Klages, N., Arboit, P., Pandey, R., Brady, D., Vaughan, S., Holder, A. A., Pain, A., Ferguson, D. J., Hainard, A., Tewari, R., \& Brochet, M. (2020). A divergent cyclin/cyclin-dependent kinase complex controls the atypical replication of a malaria parasite during gametogony and transmission. eLife, 9, e56474. https://doi.org/10.7554/eLife.56474

8. Banterle, N., Nievergelt, A. P., de Buhr, S., Hatzopoulos, G. N., Brillard, C., Andany, S., Hübscher, T., Sorgenfrei, F., Sch warz, U. S., Gräter, F., Fantner, G. E., \& Gönczy, P. (2020). Surface-catalyzed SAS-6 self-assembly directs centriole formation through kinetic and structural mechanisms [Preprint]. Biophysics. https://doi.org/10.1101/2020.09.04.283184

9. Berry, L., Chen, C.-T., Francia, M. E., Guerin, A., Graindorge, A., Saliou, J.-M., Grandmougin, M., Wein, S., Bechara, C., MorlonGuyot, J., Bordat, Y., Gubbels, M.-J., Lebrun, M., Dubremetz, J.-F., \& Daher, W. (2018). Toxoplasma gondii chromosomal passenger complex is essential for the organization of a functional mitotic spindle: A prerequisite for productive endodyogeny. Cellular and Molecular Life Sciences : CMLS, 75(23), 4417-4443. PubMed. https://doi.org/10.1007/s00018-018-2889-6

10. Berry, L., Chen, C.-T., Reininger, L., Carvalho, T. G., El Hajj, H., Morlon-Guyot, J., Bordat, Y., Lebrun, M., Gubbels, M.-J., Doerig, C., \& Daher, W. (2016). The conserved apicomplexan Aurora kinase TgArk3 is involved in endodyogeny, duplication rate and parasite virulence. Cellular Microbiology, 18(8), 1106-1120. PubMed. https://doi.org/10.1111/cmi.12571

11. Bertiaux, E., Balestra, A. C., Bournonville, L., Louvel, V., Maco, B., Soldati-Favre, D., Brochet, M., Guichard, P., \& Hamel, V. (2021). Expansion microscopy provides new insights into the cytoskeleton of malaria parasites including the conservation of a conoid. PLOS Biology, 19(3), e3001020. https://doi.org/10.1371/journal.pbio.3001020

12. Bettencourt-Dias, M., Rodrigues-Martins, A., Carpenter, L., Riparbelli, M., Lehmann, L., Gatt, M. K., Carmo, N., Balloux, F., Callaini, G., \& Glover, D. M. (2005). SAK/PLK4 Is Required for Centriole Duplication and Flagella Development. Current Biology, 15(24), 2199-2207. https://doi.org/10.1016/j.cub.2005.11.042

13. Bhattacharyya, M. K., Hong, Z., Kongkasuriyachai, D., \& Kumar, N. (2002). Plasmodium falciparum protein phosphatase type 1 functionally complements a glc7 mutant in Saccharomyces cerevisiae. International Journal for Parasitology, 32(6), 739-747. https://doi.org/10.1016/s0020-7519(02)00007-3

14. Boveri, T. (1887). Ueber den Antheil des Spermatozoon an der Teilung des Eies. Sitzungsber. Ges. Morph. Physiol., 3, 151-164.

15. Bracchi-Ricard, V., Barik, S., Delvecchio, C., Doerig, C., Chakrabarti, R., \& Chakrabarti, D. (2000). PfPK6, a novel cyclin-dependent kinase/mitogen-activated protein kinase-related protein kinase from Plasmodium falciparum. 9.

16. Brooks, C. F., Francia, M. E., Gissot, M., Croken, M. M., Kim, K., \& Striepen, B. (2011). <em>Toxoplasma gondii</em> sequesters centromeres to a specific nuclear region throughout the cell cycle. Proceedings of the National Academy of Sciences, $108(9), 3767$. https://doi.org/10.1073/pnas.1006741108

17. Canning, E. U., \& Sinden, R. E. (1973). The organization of the ookinete and observations on nuclear division in oocysts of Plasmodium berghei. Parasitology, 67(1), 29-40. https://doi.org/10.1017/s0031182000046266

18. Carvalho, T. G., Doerig, C., \& Reininger, L. (2013). Nima- and Aurora-related kinases of malaria parasites. Inhibitors of Protein Kinases, 1834(7), 1336-1345. https://doi.org/10.1016/j.bbapap.2013.02.022 
19. Carvalho-Santos, Z., Machado, P., Branco, P., Tavares-Cadete, F., Rodrigues-Martins, A., Pereira-Leal, J. B., \& Bettencourt-Dias, M. (2010). Stepwise evolution of the centriole-assembly pathway. Journal of Cell Science, 123(Pt 9), 1414-1426. https://doi.org/10.1242/jcs.064931

20. Chen, C.-T., \& Gubbels, M.-J. (2013). The Toxoplasma gondii centrosome is the platform for internal daughter budding as revealed by a Nek1 kinase mutant. Journal of Cell Science, jcs.123364. https://doi.org/10.1242/jcs.123364

21. Chen, C.-T., \& Gubbels, M.-J. (2019). TgCep250 is dynamically processed through the division cycle and is essential for structural integrity of the Toxoplasma centrosome. Molecular Biology of the Cell, 30(10), 1160-1169. https://doi.org/10.1091/mbc.E18$10-0608$

22. Chen, C.-T., Kelly, M., Leon, J. de, Nwagbara, B., Ebbert, P., Ferguson, D. J. P., Lowery, L. A., Morrissette, N., \& Gubbels, M.-J. (2015). Compartmentalized Toxoplasma EB1 bundles spindle microtubules to secure accurate chromosome segregation. Molecular Biology of the Cell, 26(25), 4562-4576. https://doi.org/10.1091/mbc.E15-06-0437

23. Courjol, F., \& Gissot, M. (2018). A coiled-coil protein is required for coordination of karyokinesis and cytokinesis in Toxoplasma gondii. Cellular Microbiology, 20(6), e12832. https://doi.org/10.1111/cmi.12832

24. Culver, B. P., Meehl, J. B., Giddings, T. H., Jr, \& Winey, M. (2009). The two SAS-6 homologs in Tetrahymena thermophila have distinct functions in basal body assembly. Molecular Biology of the Cell, 20(6), 1865-1877. PubMed. https://doi.org/10.1091/mbc.e08-08-0838

25. Daher, W., Oria, G., Fauquenoy, S., Cailliau, K., Browaeys, E., Tomavo, S., \& Khalife, J. (2007). A Toxoplasma gondii leucinerich repeat protein binds phosphatase type 1 protein and negatively regulates its activity. Eukaryotic Cell, 6(9), 1606-1617. PubMed. https://doi.org/10.1128/EC.00260-07

26. Dammermann, A., Müller-Reichert, T., Pelletier, L., Habermann, B., Desai, A., \& Oegema, K. (2004). Centriole assembly requires both centriolar and pericentriolar material proteins. Developmental Cell, 7(6), 815-829. https://doi.org/10.1016/j.devcel.2004.10.015

27. Danielsson, F., Mahdessian, D., Axelsson, U., Sullivan, D., Uhlén, M., Andersen, J. S., Thul, P. J., \& Lundberg, E. (2020). Spatial Characterization of the Human Centrosome Proteome Opens Up New Horizons for a Small but Versatile Organelle. PROTEOMICS, 20(23), 1900361. https://doi.org/10.1002/pmic.201900361

28. de Leon, J. C., Scheumann, N., Beatty, W., Beck, J. R., Tran, J. Q., Yau, C., Bradley, P. J., Gull, K., Wickstead, B., \& Morrissette, N. S. (2013). A SAS-6-like protein suggests that the Toxoplasma conoid complex evolved from flagellar components. Eukaryotic Cell, 12(7), 1009-1019. https://doi.org/10.1128/EC.00096-13

29. Delorme, V., Garcia, A., Cayla, X., \& Tardieux, I. (2002). A role for Toxoplasma gondii type 1 ser/thr protein phosphatase in host cell invasion. Microbes and Infection, 4(3), 271-278. https://doi.org/10.1016/s1286-4579(02)01538-1

30. Deshmukh, A. S., Agarwal, M., \& Dhar, S. K. (2016). Regulation of DNA replication proteins in parasitic protozoans: Possible role of CDK-like kinases. Current Genetics, 62(3), 481-486. https://doi.org/10.1007/s00294-015-0562-2

31. Deveuve, Q., Lesage, K., Mouveaux, T., \& Gissot, M. (2017). The Toxoplasma gondii inhibitor-2 regulates protein phosphatase 1 activity through multiple motifs. Parasitology Research, 116(9), 2417-2426. https://doi.org/10.1007/s00436-017-5543-6

32. Dorin-Semblat, D., Schmitt, S., Semblat, J.-P., Sicard, A., Reininger, L., Goldring, D., Patterson, S., Quashie, N., Chakrabarti, D., Meijer, L., \& Doerig, C. (2011). Plasmodium falciparum NIMA-related kinase Pfnek-1: Sex specificity and assessment of essentiality for the erythrocytic asexual cycle. Microbiology (Reading, England), 157(Pt 10), 2785-2794. PubMed. https://doi.org/10.1099/mic.0.049023-0

33. Dos Santos Pacheco Nicolas, Tosetti Nicolò, Krishnan Aarti, Haase Romuald, Maco Bohumil, Suarez Catherine, Ren Bingjian, Soldati-Favre Dominique, \& Boyle Jon P. (2021). Revisiting the Role of Toxoplasma gondii ERK7 in the Maintenance and Stability of the Apical Complex. mBio, 12(5), e02057-21. https://doi.org/10.1128/mBio.02057-21

34. Dubremetz, J. F. (1973). [Ultrastructural study of schizogonic mitosis in the coccidian, Eimeria necatrix (Johnson 1930)]. Journal of ultrastructure research, 42(3), 354-376.

35. Dubremetz, J.-F. (1971). . L'ultrastructure du centriole et du centrocone chez la coccidie eimeria necatrix. É tude au cours de la schizogonie. 23, 453-458.

36. Eto, M., Elliott, E., Prickett, T. D., \& Brautigan, D. L. (2002). Inhibitor-2 Regulates Protein Phosphatase-1 Complexed with NimArelated Kinase to Induce Centrosome Separation *. Journal of Biological Chemistry, 277(46), 44013-44020. https://doi.org/10.1074/jbc.M208035200

37. Farhat, D. C., Swale, C., Dard, C., Cannella, D., Ortet, P., Barakat, M., Sindikubwabo, F., Belmudes, L., De Bock, P.-J., Couté, Y., Bougdour, A., \& Hakimi, M.-A. (2020). A MORC-driven transcriptional switch controls Toxoplasma developmental trajectories and sexual commitment. Nature Microbiology, 5(4), 570-583. https://doi.org/10.1038/s41564-020-0674-4 
38. Farrell, M., \& Gubbels, M.-J. (2014). The Toxoplasma gondii kinetochore is required for centrosome association with the centrocone (spindle pole). Cellular Microbiology, 16(1), 78-94. https://doi.org/10.1111/cmi.12185

39. Fowler, R. E., Smith, A. M., Whitehorn, J., Williams, I. T., Bannister, L. H., \& Mitchell, G. H. (2001). Microtubule associated motor proteins of Plasmodium falciparum merozoites. Molecular and Biochemical Parasitology, 117(2), 187-200. https://doi.org/10.1016/s0166-6851(01)00351-6

40. Francia, M. E., Bhavsar, S., Ting, L.-M., Croken, M. M., Kim, K., Dubremetz, J.-F., \& Striepen, B. (2020). A Homolog of Structural Maintenance of Chromosome 1 Is a Persistent Centromeric Protein Which Associates With Nuclear Pore Components in Toxoplasma gondii. Frontiers in Cellular and Infection Microbiology, 10, 295. https://doi.org/10.3389/fcimb.2020.00295

41. Francia, M. E., Dubremetz, J.-F., \& Morrissette, N. S. (2015). Basal body structure and composition in the apicomplexans Toxoplasma and Plasmodium. Cilia, 5(1), 3. https://doi.org/10.1186/s13630-016-0025-5

42. Francia, M. E., Jordan, C. N., Patel, J. D., Sheiner, L., Demerly, J. L., Fellows, J. D., de Leon, J. C., Morrissette, N. S., Dubremetz, J.-F., \& Striepen, B. (2012). Cell Division in Apicomplexan Parasites Is Organized by a Homolog of the Striated Rootlet Fiber of Algal Flagella. PLoS Biology, 10(12), e1001444. https://doi.org/10.1371/journal.pbio.1001444

43. Francia, M. E., \& Striepen, B. (2014). Cell division in apicomplexan parasites. Nature Reviews Microbiology, 12(2), 125-136. https://doi.org/10.1038/nrmicro3184

44. Galjart, N. (2010). Plus-end-tracking proteins and their interactions at microtubule ends. Current Biology : CB, 20(12), R528-537. https://doi.org/10.1016/j.cub.2010.05.022

45. Ganter, M., Goldberg, J. M., Dvorin, J. D., Paulo, J. A., King, J. G., Tripathi, A. K., Paul, A. S., Yang, J., Coppens, I., Jiang, R. H. Y., Elsworth, B., Baker, D. A., Dinglasan, R. R., Gygi, S. P., \& Duraisingh, M. T. (2017). Plasmodium falciparum CRK4 directs continuous rounds of DNA replication during schizogony. Nature Microbiology, 2, 17017. PubMed. https://doi.org/10.1038/nmicrobiol.2017.17

46. Gerald, N., Mahajan, B., \& Kumar, S. (2011). Mitosis in the human malaria parasite Plasmodium falciparum. Eukaryotic Cell, 10(4), 474-482. https://doi.org/10.1128/EC.00314-10

47. Gnangnon, B., Fréville, A., Cailliau, K., Leroy, C., De Witte, C., Tulasne, D., Martoriarti, A., Jung, V., Guerrera, I. C., Marion, S., Khalife, J., \& Pierrot, C. (2019). Plasmodium pseudo-Tyrosine Kinase-like binds PP1 and SERA5 and is exported to host erythrocytes. Scientific Reports, 9(1), 8120. https://doi.org/10.1038/s41598-019-44542-3

48. Gopalakrishnan, J., Guichard, P., Smith, A. H., Schwarz, H., Agard, D. A., Marco, S., \& Avidor-Reiss, T. (2010). Self-assembling SAS-6 Multimer Is a Core Centriole Building Block. Journal of Biological Chemistry, 285(12), 8759-8770. https://doi.org/10.1074/jbc.M109.092627

49. Gubbels, M.-J., Coppens, I., Zarringhalam, K., Duraisingh, M. T., \& Engelberg, K. (2021). The Modular Circuitry of Apicomplexan Cell Division Plasticity. Frontiers in Cellular and Infection Microbiology, 11, 670049. https://doi.org/10.3389/fcimb.2021.670049

50. Gubbels, M.-J., Vaishnava, S., Boot, N., Dubremetz, J.-F., \& Striepen, B. (2006). A MORN-repeat protein is a dynamic component of the Toxoplasma gondii cell division apparatus. Journal of Cell Science, 119(11), 2236-2245. https://doi.org/10.1242/jcs.02949

51. Guizetti, J., \& Frischknecht, F. (2021). Apicomplexans: A conoid ring unites them all. PLOS Biology, 19(3), e3001105. https://doi.org/10.1371/journal.pbio.3001105

52. Guttery, D. S., Poulin, B., Ramaprasad, A., Wall, R. J., Ferguson, D. J. P., Brady, D., Patzewitz, E.-M., Whipple, S., Straschil, U., Wright, M. H., Mohamed, A. M. A. H., Radhakrishnan, A., Arold, S. T., Tate, E. W., Holder, A. A., Wickstead, B., Pain, A., \& Tewari, R. (2014). Genome-wide functional analysis of Plasmodium protein phosphatases reveals key regulators of parasite development and differentiation. Cell Host E Microbe, 16(1), 128-140. PubMed. https://doi.org/10.1016/j.chom.2014.05.020

53. Harding, C. R., \& Frischknecht, F. (2020). The Riveting Cellular Structures of Apicomplexan Parasites. Trends in Parasitology, 36(12), 979-991. https://doi.org/10.1016/j.pt.2020.09.001

54. Hardy, T., Lee, M., Hames, R. S., Prosser, S. L., Cheary, D.-M., Samant, M. D., Schultz, F., Baxter, J. E., Rhee, K., \& Fry, A. M. (2014). Multisite phosphorylation of C-Nap1 releases it from Cep135 to trigger centrosome disjunction. Journal of Cell Science, 127(11), 2493-2506. https://doi.org/10.1242/jcs.142331

55. Hepler, P. K., Huff, C. G., \& Sprinz, H. (1966). THE FINE STRUCTURE OF THE EXOERYTHROCYTIC STAGES OF PLASMODIUM FALLAX. Journal of Cell Biology, 30(2), 333-358. https://doi.org/10.1083/jcb.30.2.333

56. Heroes, E., Lesage, B., Görnemann, J., Beullens, M., Van Meervelt, L., \& Bollen, M. (2013). The PP1 binding code: A molecularlego strategy that governs specificity. The FEBS Journal, 280(2), 584-595. https://doi.org/10.1111/j.1742-4658.2012.08547.x 
57. Hodges, M. E., Scheumann, N., Wickstead, B., Langdale, J. A., \& Gull, K. (2010). Reconstructing the evolutionary history of the centriole from protein components. Journal of Cell Science, 123(9), 1407-1413. https://doi.org/10.1242/jcs.064873

58. Hollin, T., De Witte, C., Fréville, A., Guerrera, I. C., Chhuon, C., Saliou, J.-M., Herbert, F., Pierrot, C., \& Khalife, J. (2019). Essential role of GEXP15, a specific Protein Phosphatase type 1 partner, in Plasmodium berghei in asexual erythrocytic proliferation and transmission. PLOS Pathogens, 15(7), e1007973. https://doi.org/10.1371/journal.ppat.1007973

59. Hu, K., Johnson, J., Florens, L., Fraunholz, M., Suravajjala, S., DiLullo, C., Yates, J., Roos, D. S., \& Murray, J. M. (2006). Cytoskeletal Components of an Invasion Machine-The Apical Complex of Toxoplasma gondii. PLOS Pathogens, $2(2)$, e13. https://doi.org/10.1371/journal.ppat.0020013

60. Katris, N. J., van Dooren, G. G., McMillan, P. J., Hanssen, E., Tilley, L., \& Waller, R. F. (2014). The Apical Complex Provides a Regulated Gateway for Secretion of Invasion Factors in Toxoplasma. PLoS Pathogens, 10(4), e1004074. https://doi.org/10.1371/journal.ppat.1004074

61. Kelley, G. L., \& Hammond, D. M. (1972). Fine structural aspects of early development of Eimeria ninakohlyakimovae in cultured cells. Zeitschrift Fur Parasitenkunde (Berlin, Germany), 38(4), 271-284. https://doi.org/10.1007/BF00329274

62. Khalife, J., Fréville, A., Gnangnon, B., \& Pierrot, C. (2021). The Multifaceted Role of Protein Phosphatase 1 in Plasmodium. Trends in Parasitology, 37(2), 154-164. https://doi.org/10.1016/j.pt.2020.09.003

63. Kilmartin, J. V. (2003). Sfi1p has conserved centrin-binding sites and an essential function in budding yeast spindle pole body duplication. The Journal of Cell Biology, 162(7), 1211-1221. PubMed. https://doi.org/10.1083/jcb.200307064

64. Kitagawa, D., Vakonakis, I., Olieric, N., Hilbert, M., Keller, D., Olieric, V., Bortfeld, M., Erat, M. C., Flückiger, I., Gönczy, P., \& Steinmetz, M. O. (2011). Structural basis of the 9-fold symmetry of centrioles. Cell, 144(3), 364-375. PubMed. https://doi.org/10.1016/j.cell.2011.01.008

65. Kollman, J. M., Polka, J. K., Zelter, A., Davis, T. N., \& Agard, D. A. (2010). Microtubule nucleating gamma-TuSC assembles structures with 13-fold microtubule-like symmetry. Nature, 466(7308), 879-882. https://doi.org/10.1038/nature09207

66. Kudryashev, M., Lepper, S., Stanway, R., Bohn, S., Baumeister, W., Cyrklaff, M., \& Frischknecht, F. (2010). Positioning of large organelles by a membrane- associated cytoskeleton in Plasmodium sporozoites. Cellular Microbiology, 12(3), 362-371. https://doi.org/10.1111/j.1462-5822.2009.01399.x

67. Lechtreck, K.-F., Rostmann, J., \& Grunow, A. (2002). Analysis of Chlamydomonas SF-assemblin by GFP tagging and expression of antisense constructs. Journal of Cell Science, 115(Pt 7), 1511-1522.

68. Lee, V. D., \& Huang, B. (1993). Molecular cloning and centrosomal localization of human caltractin. Proceedings of the National Academy of Sciences, 90(23), 11039. https://doi.org/10.1073/pnas.90.23.11039

69. Leidel, S., Delattre, M., Cerutti, L., Baumer, K., \& Gönczy, P. (2005). SAS-6 defines a protein family required for centrosome duplication in C. elegans and in human cells. Nature Cell Biology, 7(2), 115-125. https://doi.org/10.1038/ncb1220

70. Leung, J. M., Liu, J., Wetzel, L. A., \& Hu, K. (2019). Centrin2 from the human parasite Toxoplasma gondii is required for its invasion and intracellular replication. Journal of Cell Science, 132(13), jcs228791. PubMed. https://doi.org/10.1242/jcs.228791

71. Liffner, B., \& Absalon, S. (2021). Expansion microsopy reveals <em $>$ Plasmodium falciparum $</$ em $>$ blood-stage parasites undergo anaphase with a chromatin bridge in the absence of mini-chromosome maintenance complex binding protein. bioRxiv, 2021.09.25.461816. https://doi.org/10.1101/2021.09.25.461816

72. Lin, Y.-C., Chang, C.-W., Hsu, W.-B., Tang, C.-J. C., Lin, Y.-N., Chou, E.-J., Wu, C.-T., \& Tang, T. K. (2013). Human microcephaly protein CEP135 binds to hSAS-6 and CPAP, and is required for centriole assembly. The EMBO Journal, 32(8), 1141-1154. https://doi.org/10.1038/emboj.2013.56

73. Marques, S. R., Ramakrishnan, C., Carzaniga, R., Blagborough, A. M., Delves, M. J., Talman, A. M., \& Sinden, R. E. (2015). An essential role of the basal body protein SAS-6 in Plasmodium male gamete development and malaria transmission. Cellular Microbiology, 17(2), 191-206. https://doi.org/10.1111/cmi.12355

74. Martorelli Di Genova, B., Wilson, S. K., Dubey, J. P., \& Knoll, L. J. (2019). Intestinal delta-6-desaturase activity determines host range for Toxoplasma sexual reproduction. PLoS Biology, 17(8), e3000364. https://doi.org/10.1371/journal.pbio.3000364

75. Matthews, H., Duffy, C. W., \& Merrick, C. J. (2018). Checks and balances? DNA replication and the cell cycle in Plasmodium. Parasites \& Vectors, 11(1), 216. https://doi.org/10.1186/s13071-018-2800-1

76. Moorhead, G. B. G., De Wever, V., Templeton, G., \& Kerk, D. (2008). Evolution of protein phosphatases in plants and animals. Biochemical Journal, 417(2), 401-409. https://doi.org/10.1042/BJ20081986 
77. Morahan, B. J., Abrie, C., Al-Hasani, K., Batty, M. B., Corey, V., Cowell, A. N., Niemand, J., Winzeler, E. A., Birkholtz, L.-M., Doerig, C., \& Garcia-Bustos, J. F. (2020). Human Aurora kinase inhibitor Hesperadin reveals epistatic interaction between Plasmodium falciparum PfArk1 and PfNek1 kinases. Communications Biology, 3(1), 701. https://doi.org/10.1038/s42003-020-01424-z

78. Morlon-Guyot, J., Francia, M. E., Dubremetz, J.-F., \& Daher, W. (2017). Towards a molecular architecture of the centrosome in Toxoplasma gondii. Cytoskeleton, 74(2), 55-71. https://doi.org/10.1002/cm.21353

79. Morrissette, N. (2015). Targeting Toxoplasma tubules: Tubulin, microtubules, and associated proteins in a human pathogen. Eukaryotic Cell, 14(1), 2-12. https://doi.org/10.1128/EC.00225-14

80. Morrissette, N., \& Gubbels, M.-J. (2014). Chapter 13-The Toxoplasma Cytoskeleton: Structures, Proteins and Processes. En L. M. Weiss \& K. Kim (Eds.), Toxoplasma Gondii (Second Edition) (pp. 455-503). Academic Press. https://doi.org/10.1016/B978-0-12396481-6.00013-1

81. Morrissette, N. S., \& Sibley, L. D. (2002a). Cytoskeleton of apicomplexan parasites. Microbiology and Molecular Biology Reviews : MMBR, 66(1), 21-38; table of contents. https://doi.org/10.1128/MMBR.66.1.21-38.2002

82. Morrissette, N. S., \& Sibley, L. D. (2002b). Disruption of microtubules uncouples budding and nuclear division in Toxoplasma gondii. Journal of Cell Science, 115(Pt 5), 1017-1025.

83. Nichols, B. A., \& Chiappino, M. L. (1987). Cytoskeleton of Toxoplasma gondii. The Journal of Protozoology, 34(2), 217-226. https://doi.org/10.1111/j.1550-7408.1987.tb03162.x

84. O’Toole, E. T., McDonald, K. L., Mäntler, J., McIntosh, J. R., Hyman, A. A., \& Müller-Reichert, T. (2003). Morphologically distinct microtubule ends in the mitotic centrosome of Caenorhabditis elegans. The Journal of Cell Biology, 163(3), 451-456. https://doi.org/10.1083/jcb.200304035

85. Paul, A. S., Miliu, A., Paulo, J. A., Goldberg, J. M., Bonilla, A. M., Berry, L., Seveno, M., Braun-Breton, C., Kosber, A. L., Elsworth, B., Arriola, J. S. N., Lebrun, M., Gygi, S. P., Lamarque, M. H., \& Duraisingh, M. T. (2020). Co-option of Plasmodium falciparum PP1 for egress from host erythrocytes. Nature Communications, 11(1), 3532. https://doi.org/10.1038/s41467-020-17306-1

86. Peixoto, L., Chen, F., Harb, O. S., Davis, P. H., Beiting, D. P., Brownback, C. S., Ouloguem, D., \& Roos, D. S. (2010). Integrative Genomic Approaches Highlight a Family of Parasite-Specific Kinases that Regulate Host Responses. Cell Host $\mathcal{E}$ Microbe, 8(2), 208-218. https://doi.org/10.1016/j.chom.2010.07.004

87. Pelletier, L., O’Toole, E., Schwager, A., Hyman, A. A., \& Müller-Reichert, T. (2006). Centriole assembly in Caenorhabditis elegans. Nature, 444(7119), 619-623. https://doi.org/10.1038/nature05318

88. Pierrot, C., Zhang, X., Zanghi, G., Fréville, A., Rebollo, A., \& Khalife, J. (2018). Peptides derived from Plasmodium falciparum leucine-rich repeat 1 bind to serine/threonine phosphatase type 1 and inhibit parasite growth in vitro. Drug Design, Development and Therapy, 12, 85-88. PubMed. https://doi.org/10.2147/DDDT.S153095

89. Ramakrishnan, C., Maier, S., Walker, R. A., Rehrauer, H., Joekel, D. E., Winiger, R. R., Basso, W. U., Grigg, M. E., Hehl, A. B., Deplazes, P., \& Smith, N. C. (2019). An experimental genetically attenuated live vaccine to prevent transmission of Toxoplasma gondii by cats. Scientific Reports, 9(1), 1474. https://doi.org/10.1038/s41598-018-37671-8

90. Rashpa, R., \& Brochet, M. (2021). Ultrastructure expansion microscopy of Plasmodium gametocytes reveals the molecular architecture of a microtubule organisation centre coordinating mitosis with axoneme assembly [Preprint]. Microbiology. https://doi.org/10.1101/2021.07.21.453039

91. Read, M., Sherwin, T., Holloway, S. P., Keith Gull, \& Hyde, J. E. (1993). Microtubular organization visualized by immunofluorescence microscopy during erythrocytic schizogony in Plasmodium falciparum and investigation of post-translational modifications of parasite tubulin. Parasitology. https://doi.org/10.1017/s0031182000075041

92. Reininger, L., Billker, O., Tewari, R., Mukhopadhyay, A., Fennell, C., Dorin-Semblat, D., Doerig, C., Goldring, D., Harmse, L., Ranford-Cartwright, L., Packer, J., \& Doerig, C. (2005). A NIMA-related Protein Kinase Is Essential for Completion of the Sexual Cycle of Malaria Parasites *. Journal of Biological Chemistry, 280(36), 31957-31964. https://doi.org/10.1074/jbc.M504523200

93. Reininger, L., Tewari, R., Fennell, C., Holland, Z., Goldring, D., Ranford-Cartwright, L., Billker, O., \& Doerig, C. (2009). An essential role for the Plasmodium Nek-2 Nima-related protein kinase in the sexual development of malaria parasites. The Journal of Biological Chemistry, 284(31), 20858-20868. PubMed. https://doi.org/10.1074/jbc.M109.017988

94. Reininger, L., Wilkes, J. M., Bourgade, H., Miranda-Saavedra, D., \& Doerig, C. (2011). An essential Aurora-related kinase transiently associates with spindle pole bodies during Plasmodium falciparum erythrocytic schizogony. Molecular Microbiology, 79(1), 205-221. PubMed. https://doi.org/10.1111/j.1365-2958.2010.07442.x 
95. Roques, M., Stanway, R. R., Rea, E. I., Markus, R., Brady, D., Holder, A. A., Guttery, D. S., \& Tewari, R. (2019). Plasmodium centrin PbCEN-4 localizes to the putative MTOC and is dispensable for malaria parasite proliferation. Biology Open, 8(1). https://doi.org/10.1242/bio.036822

96. Roques, M., Wall, R. J., Douglass, A. P., Ramaprasad, A., Ferguson, D. J. P., Kaindama, M. L., Brusini, L., Joshi, N., Rchiad, Z., Brady, D., Guttery, D. S., Wheatley, S. P., Yamano, H., Holder, A. A., Pain, A., Wickstead, B., \& Tewari, R. (2015). Plasmodium P-Type Cyclin CYC3 Modulates Endomitotic Growth during Oocyst Development in Mosquitoes. PLOS Pathogens, 11(11), e1005273. https://doi.org/10.1371/journal.ppat.1005273

97. Russell, D. G., \& Burns, R. G. (1984). The polar ring of coccidian sporozoites: A unique microtubule-organizing centre. Journal of Cell Science, 65, 193-207.

98. Sanchez, A. D., \& Feldman, J. L. (2017). Microtubule-organizing centers: From the centrosome to non-centrosomal sites. Current Opinion in Cell Biology, 44, 93-101. https://doi.org/10.1016/j.ceb.2016.09.003

99. Scheer, U. (2014). Historical roots of centrosome research: Discovery of Boveri's microscope slides in Würzburg. Philosophical Transactions of the Royal Society B: Biological Sciences, 369(1650), 20130469. https://doi.org/10.1098/rstb.2013.0469

100. Schrével, J., Asfaux-Foucher, G., \& Bafort, J. M. (1977). Etude ultrastructurale des mitoses multiples au cours de la sporogonie $\mathrm{du}$ Plasmodium b. Berghei [Ultrastructural study of multiple mitoses during sporogony of Plasmodium b. Berghei. J Ultrastruct Res. https://doi.org/10.1016/s0022-5320(77)90043-0

101. Seybold, C., \& Schiebel, E. (2013). Spindle pole bodies. Current Biology, 23(19), R858-R860. https://doi.org/10.1016/j.cub.2013.07.024

102. Simon, C. S., Voß, Y., Funaya, C., Machado, M., Penning, A., Klaschka, D., Cyrklaff, M., Kim, J., Ganter, M., \& Guizetti, J. (2021). An extended DNA-free intranuclear compartment organizes centrosomal microtubules in Plasmodium falciparum. bioRxiv, 2021.03.12.435157. https://doi.org/10.1101/2021.03.12.435157

103. Sinden, R. E., Canning, E. U., Spain, B., \& Garnham, P. C. C. (1976). Gametogenesis and fertilization in Plasmodium yoelii nigeriensis: A transmission electron microscope study. Proceedings of the Royal Society of London. Series B. Biological Sciences, 193(1110), 55-76. https://doi.org/10.1098/rspb.1976.0031

104. Sinden, R. E., \& Smalley, M. E. (1979). Gametocytogenesis of Plasmodium falciparum in vitro: The cell-cycle. Parasitology, 79(2), 277-296. https://doi.org/10.1017/s003118200005335x

105. Slep, K. C. (2016). The Secret of Centriole Length: Keep a LID on It. Developmental Cell, $37(4)$, $293-295$. https://doi.org/10.1016/j.devcel.2016.05.008

106. Solyakov, L., Halbert, J., Alam, M. M., Semblat, J.-P., Dorin-Semblat, D., Reininger, L., Bottrill, A. R., Mistry, S., Abdi, A., Fennell, C., Holland, Z., Demarta, C., Bouza, Y., Sicard, A., Nivez, M.-P., Eschenlauer, S., Lama, T., Thomas, D. C., Sharma, P., ... Doerig, C. (2011). Global kinomic and phospho-proteomic analyses of the human malaria parasite Plasmodium falciparum. Nature Communications, 2, 565. https://doi.org/10.1038/ncomms1558

107. Striepen, B., Crawford, M. J., Shaw, M. K., Tilney, L. G., Seeber, F., \& Roos, D. S. (2000). The plastid of Toxoplasma gondii is divided by association with the centrosomes. The Journal of Cell Biology, 151(7), 1423-1434. PubMed. https://doi.org/10.1083/jcb.151.7.1423

108. Striepen, B., Jordan, C. N., Reiff, S., \& van Dooren, G. G. (2007). Building the Perfect Parasite: Cell Division in Apicomplexa. PLoS Pathogens, 3(6), e78. https://doi.org/10.1371/journal.ppat.0030078

109. Suvorova, E. S., Francia, M., Striepen, B., \& White, M. W. (2015). A Novel Bipartite Centrosome Coordinates the Apicomplexan Cell Cycle. PLOS Biology, 13(3), e1002093. https://doi.org/10.1371/journal.pbio.1002093

110. Teixidó-Travesa, N., Roig, J., \& Lüders, J. (2012). The where, when and how of microtubule nucleation -One ring to rule them all. Journal of Cell Science, 125(Pt 19), 4445-4456. https://doi.org/10.1242/jcs.106971

111. Tomasina, R., \& Francia, M. E. (2020). The Structural and Molecular Underpinnings of Gametogenesis in Toxoplasma gondii. Frontiers in Cellular and Infection Microbiology, 10, 608291. https://doi.org/10.3389/fcimb.2020.608291

112. Tran, J. Q., de Leon, J. C., Li, C., Huynh, M.-H., Beatty, W., \& Morrissette, N. S. (2010). RNG1 is a late marker of the apical polar ring in Toxoplasma gondii. Cytoskeleton, 67(9), 586-598. https://doi.org/10.1002/cm.20469

113. van der Zypen, E., \& Piekarski, G. (1967). [Endodyogeny in Toxoplasma gondii. A morphological analysis]. Zeitschrift fur Parasitenkunde (Berlin, Germany), 29(1), 15-35. https://doi.org/10.1007/BF00328836

114. Vérollet, C., Colombié, N., Daubon, T., Bourbon, H.-M., Wright, M., \& Raynaud-Messina, B. (2006). Drosophila melanogaster $\gamma$-TuRC is dispensable for targeting $\gamma$-tubulin to the centrosome and microtubule nucleation. Journal of Cell Biology, 172(4), 517528. https://doi.org/10.1083/jcb.200511071 
115. Vivier, E., \& Vickerman, K. (1974). Divisions nucléaires chez les protozoaires. Actualités Protozoologiques, 1, 161-177.

116. Wang, J. T., Kong, D., Hoerner, C. R., Loncarek, J., \& Stearns, T. (2017). Centriole triplet microtubules are required for stable centriole formation and inheritance in human cells. eLife, 6, e29061. https://doi.org/10.7554/eLife.29061

117. Woodruff, J. B., Wueseke, O., \& Hyman, A. A. (2014). Pericentriolar material structure and dynamics. Philosophical Transactions of the Royal Society B: Biological Sciences, 369(1650), 20130459. https://doi.org/10.1098/rstb.2013.0459

118. Xue, M., Giagtzoglou, N., \& Bellen, H. J. (2011). Dueling Ca2+ Sensors in Neurotransmitter Release. Cell, 147(3), 491-493. https://doi.org/10.1016/j.cell.2011.10.007

119. Yang, C., \& Arrizabalaga, G. (2017). The serine/threonine phosphatases of apicomplexan parasites. Molecular Microbiology, 106(1), 1-21. https://doi.org/10.1111/mmi.13715

120. Zeeshan, M., Pandey, R., Subudhi, A. K., Ferguson, D. J. P., Kaur, G., Rashpa, R., Nugmanova, R., Brady, D., Bottrill, A. R., Vaughan, S., Brochet, M., Bollen, M., Pain, A., Holder, A. A., Guttery, D. S., \& Tewari, R. (2021). Protein phosphatase 1 regulates atypical mitotic and meiotic division in Plasmodium sexual stages. Communications Biology, 4(1), 760. https://doi.org/10.1038/s42003-021-02273-0

121. Zitouni, S., Francia, M. E., Leal, F., Montenegro Gouveia, S., Nabais, C., Duarte, P., Gilberto, S., Brito, D., Moyer, T., KandelsLewis, S., Ohta, M., Kitagawa, D., Holland, A. J., Karsenti, E., Lorca, T., Lince-Faria, M., \& Bettencourt-Dias, M. (2016). CDK1 Prevents Unscheduled PLK4-STIL Complex Assembly in Centriole Biogenesis. Current Biology, 26(9), $1127-1137$. https://doi.org/10.1016/j.cub.2016.03.055 